\title{
EFFECTS OF CANTILEVER LENGTH AND DIAMETER OF THE CUTTING TOOL ON RESONANCE FREQUENCY IN ULTRASONIC ASSISTED MACHINING
}

\author{
Ngo Quoc Huy ${ }^{1}$, Mai Thi Thu $\mathrm{Ha}^{2}$, Nguyen Van $\mathrm{Du}^{1^{*}}$ \\ ${ }^{1} T N U$ - University of Technology \\ ${ }^{2}$ Thai Nguyen High School for Gifted Students
}

\begin{tabular}{r}
\hline ARTICLE INFO \\
\hline Received: 07/3/2021 \\
Revised: $14 / 3 / 2021$ \\
Published: $15 / 3 / 2021$ \\
KEYWORDS
\end{tabular}

Ultrasonic assisted machining

ABSTRACT

Resonance

In ultrasonic assisted machining, it is required to operate the vibratory actuator at its resonant frequency. This paper presents a quick method to determine the resonance frequency of the ultrasonic vibratory systems for different values of the diameter and the cantilever length of the cutting tool. Applying the V-I method, the resonance frequency of the ultrasonic assisted machining unit can be measured by the electrical impedance. The results showed that both the cantilever length and the diameter of the cutting tool have significant effects on the resonance frequency. Given a tool with preset diameter, the cantilever length of the cutting tool can be adjusted to make the system work with the resonance frequency of the whole. The results

Cutting tools

Cantilever length obtained thus would be promissing to apply in designing and

Tool diameter operating the vibratory unit in ultrasonic assisted machining.

\section{ẢNH HƯởNG CỦA CHIỀU DÀI CÔNG-XÔN \\ VÀ ĐƯỜNG KÍNH DAO ĐẾN TẦ SỐ CộNG HƯởNG TRONG GIA CÔNG CÓ RUNG ĐộNG SIÊUU ÂM TRỢ GIÚP}

\author{
Ngô Quốc Huy ${ }^{1}$, Mai Thị Thu Hà², Nguyễn Văn Dự ${ }^{1 *}$ \\ ${ }^{1}$ Truờng Đại học Kỹ thuật Công nghiệp - ĐH Thái Nguyên \\ ${ }^{2}$ Truờng THPT Chuyên Thái Nguyên
}

\begin{tabular}{|c|c|}
\hline THÔNG TIN BÀI BÁO & \multirow{11}{*}{ 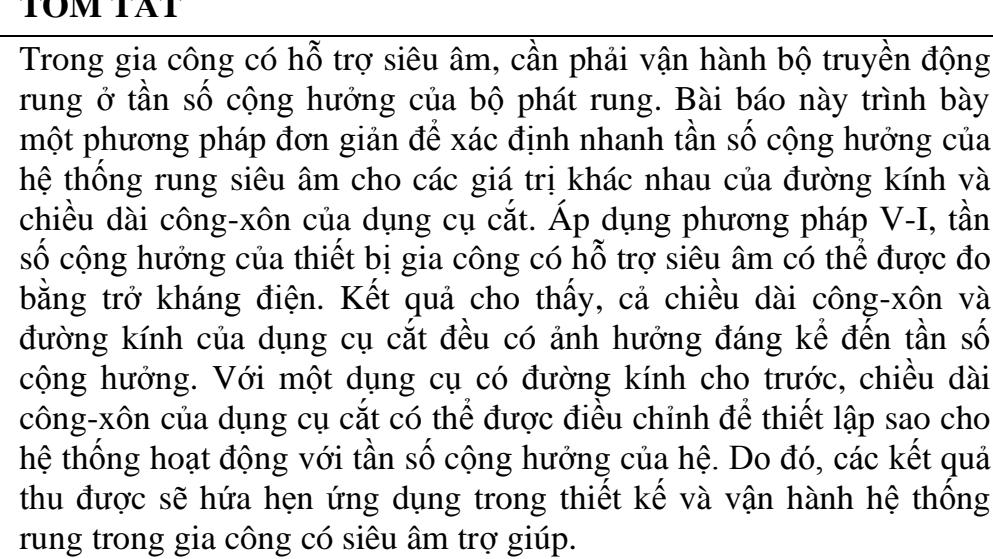 } \\
\hline Ngày nhận bài: 07/3/2021 & \\
\hline Ngày hoàn thiện: 14/3/2021 & \\
\hline Ngày đăng: 15/3/2021 & \\
\hline & \\
\hline & \\
\hline Gia công c & \\
\hline Tần số cộng hưởng & \\
\hline Dụng cụ cắt & \\
\hline hiều dài công-xôn & \\
\hline Jưng KIII dụ̂ng cụ & \\
\hline
\end{tabular}

DOI: https://doi.org/10.34238/tnu-jst.4103

\footnotetext{
* Corresponding author. Email: vandu@tnut.edu.vn
} 


\section{Introduction}

Ultrasonic assisted machining (UAM) is a technique in which vibrations with smallamplitude, high-frequency are superimposed to the relative motion between cutting tool and workpiece during the machining operation in order to achieve better cutting performance [1]. For example, abundant advantages of ultrasonic assisted drilling have been found as to provide significant reduction of thrust force [2]-[6], improvements in built-up edge [2], [7], burr size [2], [8], reduction of drilling torque [9], improving the chip evacuation [10]-[13]. In the application of ultrasonic assisted machining, the design of the vibratory unit for clamping the cutting tool is a critical issue. A vibratory unit used in UAM typically consists of a transducer, a horn or sonotrode, and the cutting tool attached to the horn. In UAM systems, the cutting tool is usually clamped in the form of a cantilever beam. It is required that the vibratory system must be operated at its resonance frequency. It has been found that the diameter of the tool, as well as the cantilever length of the tool outside the horn have significant effects on the resonance frequency of the whole system. Although abundant studies have been made for designing either the transducer or the horn [14]-[16], the effect of the tool attached on the system has not been evaluated. This paper presents a design approach to examine such effects on the resonance frequency of a typical vibratory unit for applications of ultrasonic assisted machining. A regression method is also applied to determine the resonance frequency of the system for typical values of the cutting tool.

\section{Materials and methods}

\subsection{Experimental setup}

The structure of the vibratory unit with the cutting tool attached is shown in Figure 1.

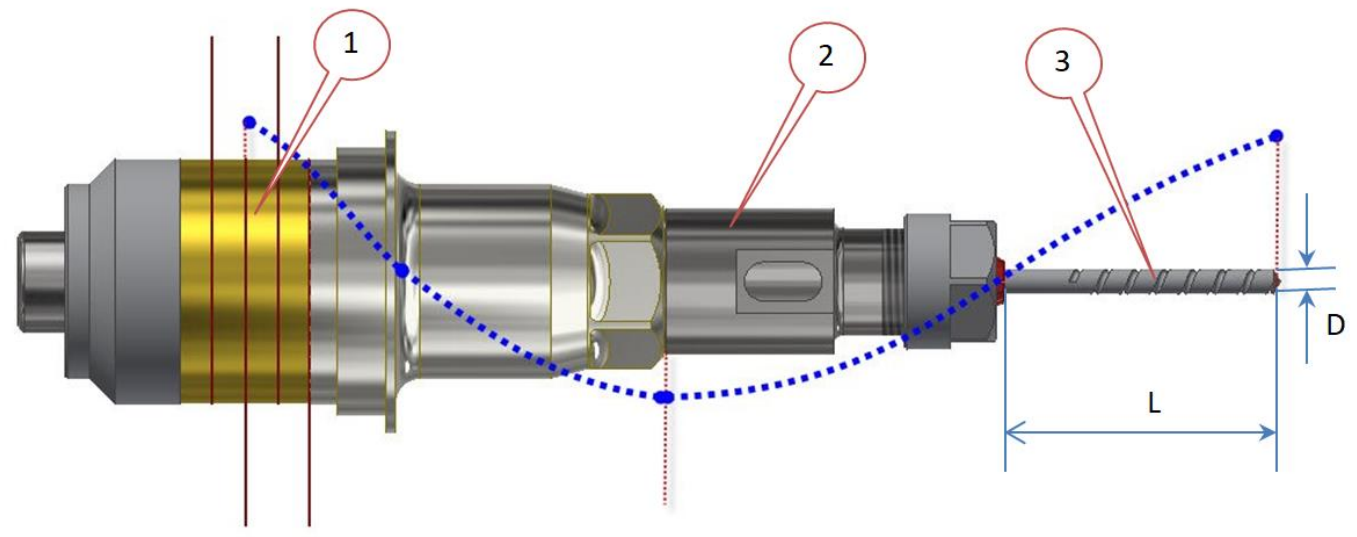

Figure 1. Assembly of the horn and the cutting tool

In Figure 1, the transducer (1) in the Langevin type has a function of converting electrical energy into a proper mechanical vibration. This kind of transducers is commercially well designed and available for ultrasonic welding applications, with a wide range of power capacity and working frequency. It is cost-effective to select a proper commercial transducer. The tool (3), having diameter (D) and cantilever length (L), is attached to the horn (2) by mean of a collet (2). The working frequency of a Langevin transducer is its actual resonant frequency, which is carefully checked and provided as the most important value from the manufacturer. The longitudinal amplitude of the ultrasonic vibration is approximately depicted by the dotted curve.

The horn (2), which is sometimes called as the centroid, plays an important role in the transmission, concentration and amplification of the ultrasonic vibration from the transducer into the tool. Hence, the geometric characteristics of the horn must be carefully determined and 
validated. It would be worth noting that any changes in dimension of the tool and/or assembly geometry will direct effect on the resonance frequency and thus on the working performance of the whole unit.

The longitudinal dimensions of the horn and the cantilever length of the tool must be computed to obtain the maximum amplitude of the vibration at the cutting lips of the tool. In this study, a collet ER16, which can be used for dill bits ranged from 1 to $7 \mathrm{~mm}$ diameter, was chosen. The detailed calculation process to determine the dimensions of a proper horn can be found in several previous studies [15]-[17].

\subsection{Measure the resonance frequency of the system}

One of the simplest method to measure the resonance frequency of the ultrasonic vibratory unit is using the total electrical impedance of the whole assembly. In this study, the impedance was measured by the V-I method [18]. A simple measurement circuit is shown in Figure 2.

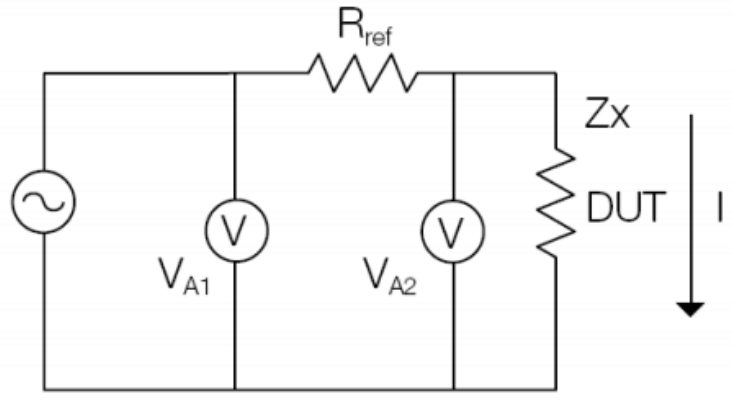

Figure 2. A simple circuit to measure ultrasonic impedance using V-I method

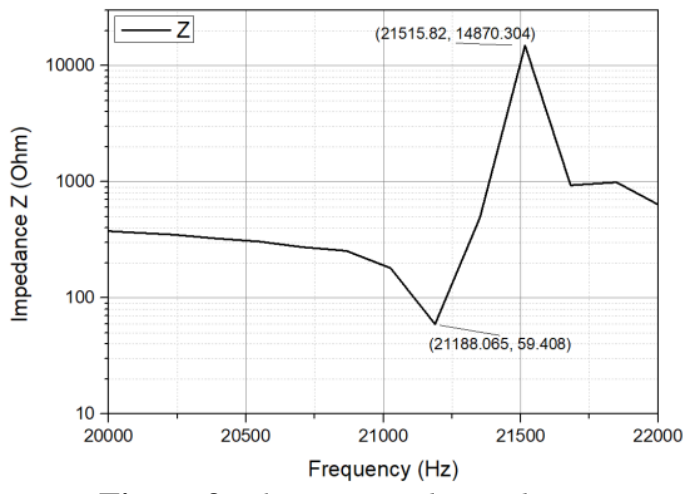

Figure 3. The measured impedance of the whole assembly

The resonance (or series resonance) frequency is the one at which the electrical impedance modulus is minimum and, therefore, the consumed current from the generator is maximum. The antiresonance (or parallel resonance) is the frequency where the electrical impedance modulus is maximum and, therefore, the consumed current from the generator is minimum. Figure 5 represents an example of the result measured by applying V-I method. Details of such measurement is explained as below.

In Figure 4, a sinusoidal signal with amplitude of $2 \mathrm{~V}$ and the swept frequency range from $15000 \mathrm{~Hz}$ to $25500 \mathrm{~Hz}$ with incremental steps of $100 \mathrm{~Hz}$ each was applied to the transducer (here is assigned as Device Under test - DUT). The voltage excitation with swept frequencies and the collection of the output signal $\mathrm{V}_{\mathrm{A} 1}, \mathrm{~V}_{\mathrm{A} 2}$ were implemented by means of a PicoScope device, named 2204A with a sampling rate of $100 \mathrm{MS} / \mathrm{s}$. The tests were implemented by mean of a special application, named FRA4PicoScope, designed for Frequency Response Analysis (FRA) capabilities. The FRA uses a common technique of frequency sweeping, and DFT extraction. The main output of each test is a Bode plot of gain (equal to the ratio of the output and input voltages) in $\mathrm{dB}$ and phase in degrees. Using the recorded values of the gain, phase corresponding to the exciatation frequency, the impedance of the ultrasonic actuator can be approximately calculated as:

$$
Z_{X}=\frac{V_{A_{2}} R_{\text {ref }}}{\sqrt{V_{A_{1}}^{2}-2 V_{A_{1}} V_{A_{2}} \cos \theta+V_{A_{2}}^{2}}}
$$

In this study, the drilling bit was chosen as a cutting tool to be examined. The diameter, D and the cantilever length, L of the cutting tool (See Figure 1) were considered as the two experimental variables. The experimental values were determined by applying the theory for Design of 
experiments, including factorial design and response design. The results were then evaluated using the Minitab®16.

\section{Results and discussions}

\subsection{Effect of the cantilever length and the diameter of the tool}

In order to examine the effect of the two factors, a two-level full factorial design was implemented. In this experimental design, each factor has only two levels and not counting center points. In this study, two replicates for experimental corner points were implemented. The values of the two variables, including cantilever length (L) and diameter (D) of the tool, and the corresponding resonance frequency (Fr) obtained are represented in Table 1.

Table 1. Design of the two-level full factorial design and results obtained

\begin{tabular}{ccccccc}
\hline StdOrder & RunOrder & CenterPt & Blocks & L ( mm) & D (mm) & Fr $(\mathbf{k H z})$ \\
\hline 5 & 1 & 1 & 1 & 40 & 3 & 22.186 \\
1 & 2 & 1 & 1 & 40 & 3 & 21.985 \\
6 & 3 & 1 & 1 & 60 & 3 & 21.188 \\
8 & 4 & 1 & 1 & 60 & 5 & 21.288 \\
3 & 5 & 1 & 1 & 40 & 5 & 21.848 \\
7 & 6 & 1 & 1 & 40 & 5 & 21.856 \\
4 & 7 & 1 & 1 & 60 & 5 & 21.256 \\
2 & 8 & 1 & 1 & 60 & 3 & 21.192 \\
\hline
\end{tabular}

The data shown in Table 1 were then analyzed to carry out the effects and interaction effects of the two factors. Figure 4 depicts the main effect plot (Figure 4a) and the interaction plot (Figure $4 b)$ for the response of the resonance frequency.

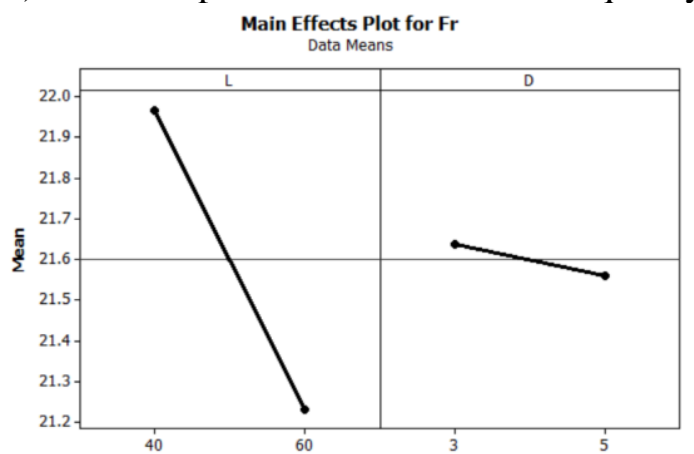

(a)

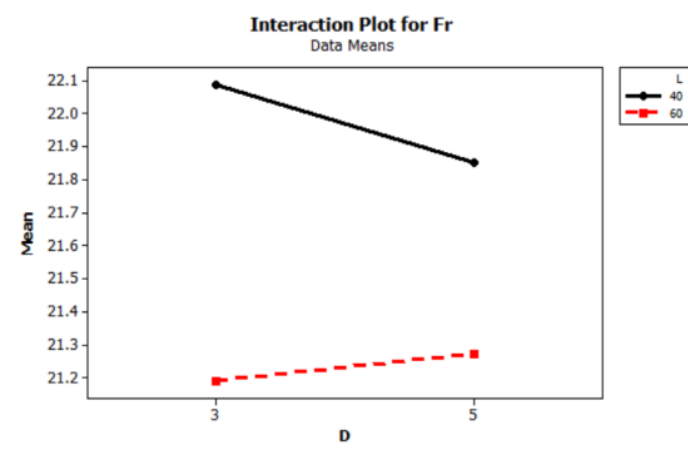

(b)

Figure 4. Main effect plot and interaction plot for resonance frequency $\mathrm{Fr}$

As can be seen in Figure 4a, the cantilever length, L, of the tool appears to have a significant effect on the resonance frequency, Fr, because the line is not horizontal. A longer cantilever length of the tool resulted in lower resonance frequency. The diameter D has a lower effect on the resonance frequency than that of the cantilever length L. Figure $4 \mathrm{~b}$ depicted the interaction effect of the two factors. As can be seen, the interaction between the two factors occurs when the change in response from the low level to the high level of one factor is not the same as the change in response at the same two levels of a second factor. In other words, the effect of the cantilever length $(\mathrm{L})$ is dependent upon the tool diameter, D. Consequently, the cantilever length of the tool should be carefully selected, depending on its diameter. 


\subsection{The operation frequency}

As confirmed above, for a certain system, having its own fixed transducer and horn, the resonance frequency depends on the cantilever length and the diameter of the tool. Hence, it is necessary to carry out the relationship of the resonance frequency with respect to such two factors. The response surface experimental design was so implemented to solve this problem. A twofactor, face-centred composite design was then experimentally realized. The design and results obtained are shown in Table 2.

Table 2. Design of the response surface design and results obtained

\begin{tabular}{ccccccc}
\hline StdOrder & RunOrder & PtType & Blocks & L (mm) & D (mm) & Fr (kHz) \\
\hline 13 & 1 & 0 & 1 & 50 & 4 & 22.016 \\
10 & 2 & 0 & 1 & 50 & 4 & 22.11 \\
2 & 3 & 1 & 1 & 60 & 3 & 21.188 \\
9 & 4 & 0 & 1 & 50 & 4 & 22.06 \\
3 & 5 & 1 & 1 & 40 & 5 & 21.848 \\
6 & 6 & -1 & 1 & 60 & 4 & 21.351 \\
4 & 7 & 1 & 1 & 60 & 5 & 21.288 \\
1 & 8 & 1 & 1 & 40 & 3 & 22.086 \\
5 & 9 & -1 & 1 & 40 & 4 & 22.016 \\
11 & 10 & 0 & 1 & 50 & 4 & 22.185 \\
8 & 11 & -1 & 1 & 50 & 5 & 21.515 \\
12 & 12 & 0 & 1 & 50 & 4 & 22.119 \\
7 & 13 & -1 & 1 & 50 & 3 & 22.016 \\
\hline
\end{tabular}

\begin{tabular}{|lrrrr|}
\hline Term & Coef & SE Coef & T & P \\
Constant & 15.2439 & 2.32808 & 6.548 & 0.000 \\
$\mathrm{~L}$ & 0.2239 & 0.08440 & 2.653 & 0.033 \\
$\mathrm{D}$ & 1.1597 & 0.72257 & 1.605 & 0.153 \\
$\mathrm{~L} \star \mathrm{L}$ & -0.0029 & 0.00080 & -3.667 & 0.008 \\
$\mathrm{D} * \mathrm{D}$ & -0.2111 & 0.07993 & -2.641 & 0.033 \\
$\mathrm{~L} * \mathrm{D}$ & 0.0085 & 0.00664 & 1.272 & 0.244 \\
& & & \\
$\mathrm{~S}=0.132836$ & PRESS $=0.968430$ & \\
$\mathrm{R}-\mathrm{Sq}=92.01 \%$ & $\mathrm{R}-\mathrm{Sq}(\mathrm{adj})=86.30 \%$ \\
\hline
\end{tabular}

Figure 5. The regression result obtained for the resonance frequency

The data obtained in Table 2 were then analyzed using regression technique and ANOVA analysis. Figure 5 shows the results captured from Minitab environment. As can be seen in the Figure, the coefficient of determination, $\mathrm{R}^{2}=92.01$ reflected that the resonance frequency $\mathrm{Fr}$ can be well modeled as a function of the cantilever length and the diameter of the tool as following:

$$
F r=15.2439+0.2239 L+1.1597 D-0.0029 L^{2}-0.2111 D^{2}+0.0085 L D
$$

The expression shown in Equation (2) was then plotted as a surface plot and contour plot in Figure 6.

As can be seen in Figure 6, the resonance frequency can be adjusted to an expected value by varying the two parameters: the cantilever length and the diameter of the tool to be clamped. Given one parameter, for example when the diameter of the cutting tool is pre-determined, one can easily calculate out the rest parameter. 


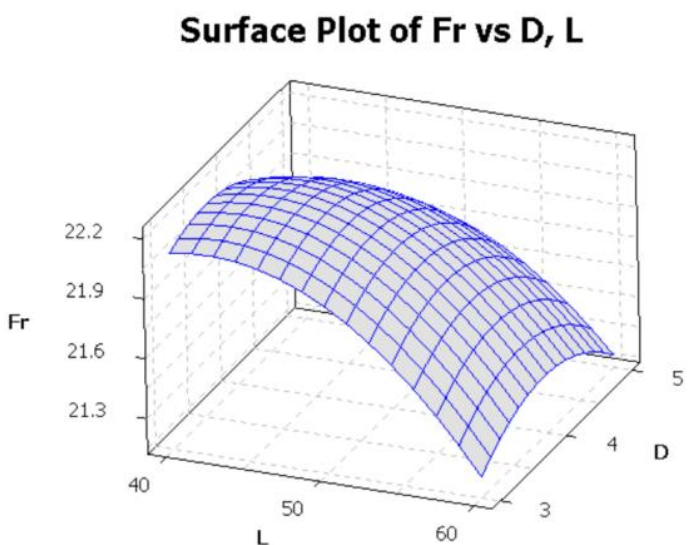

(a)

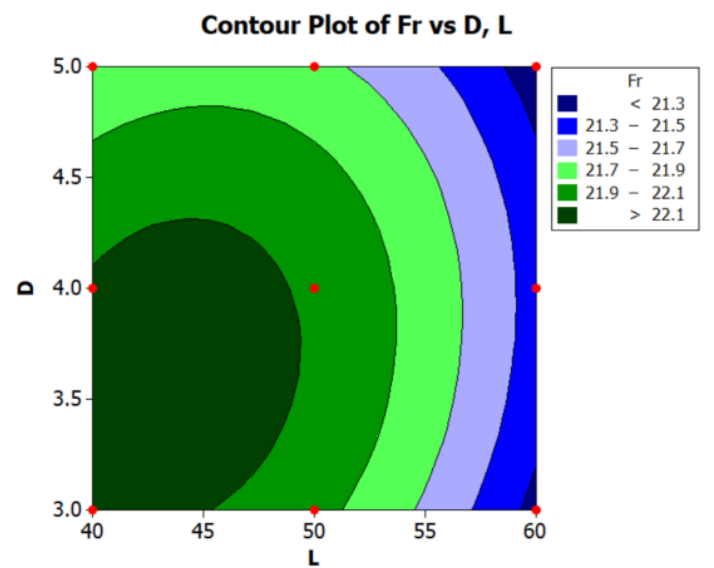

(b)

Figure 6. Surface plot (a) and contour plot (b) for resonance frequency $\mathrm{Fr}$

\section{Conclusion}

An experimental study on the effect of the cantilever length and the diameter of the cutting tool on the resonance frequency of the ultrasonic assisted machining was investigated in this study. The following remarks can be concluded:

- The cantilever length and the diameter of the cutting tool have significant effects on the resonance frequency of the vibratory system. The cantilever length has more effect on the resonance frequency than that of the tool diameter;

- After making the detailed structure of the horn and other constructions required to attach the cutting tool, the resonant frequency of the whole system should be checked. The operation frequency can be adjusted by varying the cantilever length of the tool to be attached;

- The resonant frequency of the assembled unit can be checked by measuring the electrical impedance of the transducer attached to the horn and the tool.

Further study should be done to develop a mathematical model of the relationship between the attachment structures and the resonant frequency of the whole.

\section{Acknowledgements}

This research is funded by Ministry of Education and Training of Vietnam, under grant number B2020-TNA-01.

\section{REFERENCES}

[1] D. E. Brehl and T. A. Dow, "Review of vibration-assisted machining," Precision Engineering, vol. 32, pp. 153-172, 2008.

[2] S. Amini, H. Paktinat, A. Barani, and A. F. Tehran, "Vibration Drilling of Al2024-T6," Materials and Manufacturing Processes, vol. 28, pp. 476-480, 2013.

[3] B. V. Azghandi, M. A. Kadivar, and M. R. Razfar, "An Experimental Study on Cutting Forces in Ultrasonic Assisted Drilling," Procedia CIRP, vol. 46, pp. 563-566, 2016.

[4] S. S. F. Chang and G. M. Bone, "Thrust force model for vibration-assisted drilling of aluminum 6061T6," International Journal of Machine Tools and Manufacture, vol. 49, pp. 1070-1076, 2009.

[5] X. Li, A. Meadows, V. Babitsky, and R. Parkin, "Experimental analysis on autoresonant control of ultrasonically assisted drilling," Mechatronics, vol. 29, pp. 57-66, 2015.

[6] X. F. Li, Z. G. Dong, R. K. Kang, Y. D. Wang, J. T. Liu, and Y. Zhang, "Comparison of Thrust Force in Ultrasonic Assisted Drilling and Conventional Drilling of Aluminum Alloy," Materials Science Forum, vol. 861, pp. 38-43, 2016.

[7] A. Barani, S. Amini, H. Paktinat, and A. Fadaei Tehrani, "Built-up edge investigation in vibration drilling of Al2024-T6," Ultrasonics, vol. 54, pp. 1300-1310, Jul. 2014. 
[8] S. S. F. Chang and G. M. Bone, "Burr height model for vibration assisted drilling of aluminum 6061 T6," Precision Engineering, vol. 34, pp. 369-375, 2010.

[9] R. Neugebauer and A. Stoll, "Ultrasonic application in drilling," Journal of Materials Processing Technology, vol. 149, pp. 633-639, 2004.

[10] V.-D. Nguyen and N.-H. Chu, "A Study on the Reduction of Chip Evacuation Torque in Ultrasonic Assisted Drilling Of Small and Deep Holes," International Journal of Mechanical Engineering and Technology, vol. 9, pp. 899-908, 2018.

[11] N.-H. Chu, V.-D. Nguyen, and T.-V. Do, "Ultrasonic-Assisted Cutting: A Beneficial Application for Temperature, Torque Reduction, and Cutting Ability Improvement in Deep Drilling of Al-6061," Applied Sciences, vol. 8, 2018, Art. no. 1708.

[12] N.-H. Chu, V.-D. Nguyen, and Q. H. Ngo, "Machinability enhancements of ultrasonic assisted deepdrilling of aluminum alloys," Machining Science and Technology, vol. 24, no. 01, pp. 112-135, 2019, doi: 10.1080/10910344.2019.1636267.

[13] N.-H. Chu and V.-D. Nguyen, "The Multi-Response Optimization of Machining Parameters in the Ultrasonic Assisted Deep-Hole Drilling Using Grey-Based Taguchi Method," International Journal of Mechanical and Production Engineering Research and Development, vol. 8, pp. 417-426, 2018.

[14] L.-C. Z. Wei-Xing Xu, "Ultrasonic vibration-assisted machining principle, design and application," Adv. Manuf, vol. 3, pp. 173-192, 2015.

[15] X. Li, P. Harkness, K. Worrall, R. Timoney, and M. Lucas, "A Parametric Study for the Design of an Optimized Ultrasonic Percussive Planetary Drill Tool," IEEE Trans Ultrason Ferroelectr Freq Control, vol. 64, pp. 577-589, Mar. 2017.

[16] A. P. M. Tadvi, Dr. J. Prajapati, and J. Shah, "Design and development of sonotrode for ultrasonic drilling," Proceedings of the ASME 2015 International Mechanical Engineering Congress and Exposition, 2015, pp. 1-5.

[17] V.-D. Nguyen and N.-H. Chu, "Ultrasonic-assisted deep-hole drilling," in Additive and Subtractive Manufacturing, J. P. Davim, Ed., Berlin, Germany: Walter de Gruyter GmbH, 2020.

[18] Q. Pan, D. Xiao, M. Deng, H. Ren, Y. Xu, and C. Xu, "A voltage-current method of measuring ultrasonic transducer impedance," 2013 Far East Forum on Nondestructive Evaluation/Testing: New Technology and Application, 2013, pp. 125-128. 